\title{
Influência do sentido de detonação da Fonte no piloto 4D Nodes do Campo de Lula
}

Gilberto R de Lima, Eduardo NA Urasaki, Adriana LC Triques, Felipe A Apolonio, Ana CL Azedias,Nathalia MSM da Cruz, Jose Marcelo N Cruz (PETROBRAS) \& Ziqin Yu e Luis Cypriano (CGG)

Copyright 2019, SBGf - Sociedade Brasileira de Geofísica

This paper was prepared for presentation during the $16^{\text {th }}$ International Congress of the Brazilian Geophysical Society held in Rio de Janeiro, Brazil, 19-22 August 2019.

Contents of this paper were reviewed by the Technical Committee of the $16^{\text {th }}$ International Congress of the Brazilian Geophysical Society and do not necessarily represent any position of the SBGf, its officers or members. Electronic reproduction or storage of any part of this paper for commercial purposes without the written consent of the Brazilian Geophysical Society is prohibited.

\section{Abstract}

The 4D seismic acquisition in Lula field is part of a set of auxiliary initiatives in PETROBRAS decision-making for the field and in every province of the so-called Pre-Salt of the Brazilian continental margin. Technical and economic feasibility studies have shown that 4D seismic signal expectation is very weak for the Pre-Salt reservoirs, very close to the limit of detectability of current techniques. In this situation, the repeatability of the acquisition and processing parameters (R. Calvert, 2005) is an indispensable key to the success and reliability of the results.

At the end of the acquisition period of the monitor survey, 41 sail lines (SLines) were reshooted. This SLines are grouped in the western portion of project, whose shooting direction was opposite that recorded in the base survey. During the processing all SLines (primes plus 41 reshoot) were used. At the end two sets of $4 \mathrm{D}$ volumes were generated, one of them preserving the direction of detonation in both surveys and another where 41 SLines are in the opposite direction. The result of the processing showed that the volume with base and monitor having all the SLines in the same direction presented results consistently better than the one registered with SLines in the opposite directions.

\section{Introdução}

Os muitos anos de pesquisa em geociências, aliados a uma ousada campanha de perfuração atravessando rochas de grande complexidade estrutural e diferentes propriedades físicas, no limite da tecnologia conhecida à época, brindaram a PETROBRAS com a descoberta de uma das mais promissoras províncias petrolíferas em operação no início do século XXI - o Pré Sal brasileiro.

O grande esforço multidisciplinar para tornar economicamente viável a produção de hidrocarbonetos sob condições muito adversas, tem rompido barreiras tecnológicas nas mais diversas áreas do conhecimento. A sísmica de reflexão de superfície (por cabos arrastados - streamer), uma das principais ferramentas na descoberta e início da fase de produção, foi substituída por sísmica de fundo (OBN - Ocean Bottom Nodes) que além de proporcionar melhor banda útil de sinal e separação dos campos de onda, permite também operações em zonas obstruídas e registro com completa distribuição azimutal fonte-receptor (inviabilizada por limitações ambientais para dados streamer)

Entre as ferramentas mais utilizadas para o desenvolvimento e acompanhamento da produção a sísmica 4D tem comprovada eficiência em rochas compressíveis, de elevado sinal 4D, mesmo sob condições de repetibilidade de parâmetros não ideais. Em acumulações de sinal 4D marginal, como é o caso do campo de Lula, é obrigatório que haja repetibilidade o mais perfeita possível nos parâmetros de aquisição e processamento.

Como não havia precedente técnico e operacional de aquisição e processamento 4D, em nenhuma parte do mundo, nas condições do Campo de Lula, optou-se por uma aquisição piloto, compreendendo apenas uma parte da acumulação. Outra razão determinante para realização apenas de um piloto está relacionada a dimensão do campo e a disponibilidade de Nodes no mercado, considerando prazo, logística e custos.

As especificações contratuais e recomendações gerais repassadas para a SBGS (companhia vencedora de licitação pública e responsável por ambos levantamentos) foram de que todos os parâmetros de aquisição deveriam ser repetidos. Devido a dificuldades operacionais, principalmente relacionadas com o clima, em meados do levantamento da segunda aquisição (monitor1) foi detectado que 41 SLines, no início do projeto (entre as 100 primeiras sequências), foram registradas em sentido oposto ao do levantamento base.

Durante o processamento 3D do OBN base verificou-se que o registro simultâneo do campo próximo não se prestou para corrigir a direcionalidade do arranjo da fonte devido a limitações na calibração dos hidrofones (NFHs) posicionados acima de cada conjunto de canhões.

Partindo do conhecimento adquirido com as aquisições e processamentos 4D multicomponene, full azimuth do PRM Jubarte (Thedy e outros,2015), sabendo do caráter estratégico do projeto e tendo ciência da resposta marginal prevista para este 4D, ainda durante a aquisição do levantamento monitor 1 , foram realizadas análises com os dados brutos (apenas correções de posição, camada de água e clock drift) do levantamento base que embasaram o esforço de repetição de 41 linhas ao final do período de aquisição do levantamento monitor.

\section{Método}

Os estudos foram feitas usando dois conjuntos de SLines adjacentes detonadas no mesmo sentido e em sentidos 
opostos como mostrado na Figura 1, um conjunto formado por. Na Tabela 1 oberva-se que ambos conjuntos de SLines foram adquiridas em sequência, sob as mesmas condições na camada de água, o que permite inferir condições ambientais semelhantes para o padrão de radiação da fonte em todos os tiros analisados, de cada conjunto.

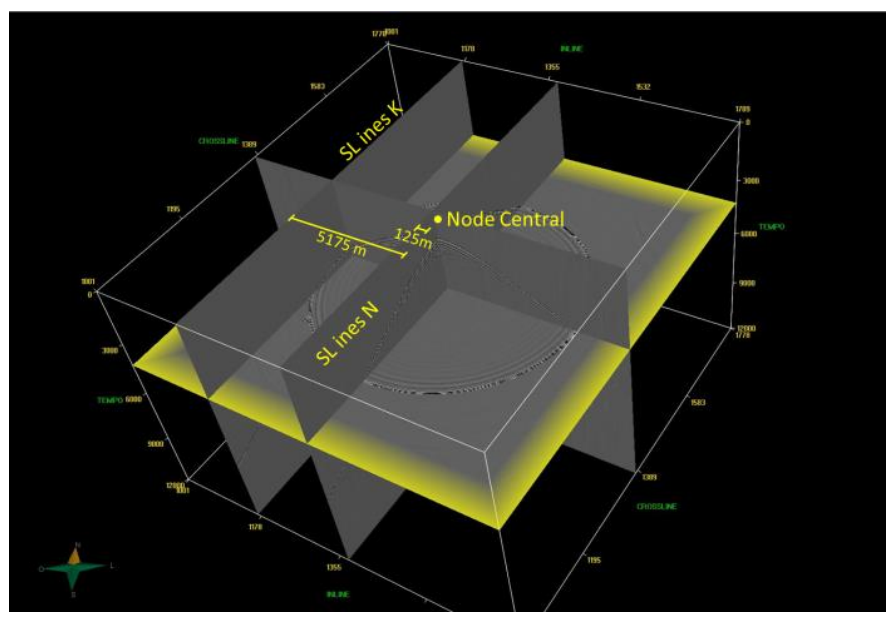

Figura 1 - Visão em perspectiva mostrando as posições relativas das SLines em relação ao Node analisado

\begin{tabular}{|c|c|c|c|c|}
\hline Sail-line & Julian day & Date & Time & Direction \\
\hline $\mathrm{N}$ & 151 & $31 /$ May/2015 & $08 \mathrm{~h} 19-10 \mathrm{~h} 23$ & $30 \mathrm{~N}$ \\
$\mathrm{~N}+1$ & 151 & $31 /$ May/2015 & $11 \mathrm{~h} 15-13 \mathrm{~h} 39$ & $210 \mathrm{~N}$ \\
$\mathrm{~N}+2$ & 151 & $31 /$ May/2015 & $14 \mathrm{~h} 33-16 \mathrm{~h} 45$ & $30 \mathrm{~N}$ \\
& & & & \\
$\mathrm{~K}$ & 174 & 23/Jun/2015 & $04 \mathrm{~h} 41-06 \mathrm{~h} 45$ & $210 \mathrm{~N}$ \\
$\mathrm{~K}+1$ & 174 & 23/Jun/2015 & $18 \mathrm{~h} 15-20 \mathrm{~h} 32$ & $30 \mathrm{~N}$ \\
$\mathrm{~K}+2$ & 175 & 24/Jun/2015 & $02 \mathrm{~h} 09-04 \mathrm{~h} 36$ & $210 \mathrm{~N}$ \\
\hline
\end{tabular}

Tabela 1 - Informações dos dois conjuntos de SLines analisadas.

A comparação entre pares de traços, numa janela de 60 $\mathrm{ms}$ em torno da onda direta, mostrou que as linhas com mesmo sentido de detonação, em ambos conjuntos, têm o mesmo e alto nível de correlação que traços adjacentes da mesma linha, enquanto linhas em sentidos opostos apresentam baixa correlação. A figura 2 mostra os resultados para o conjunto de linhas mais afastadas.

Partindo dos resultados mostrados na Figura 2, foi possível convencer a aquisição sísmica da PETROBRAS e da SBGS/CGG a montar uma logística capaz de redetonar as 41 SLines necessárias.

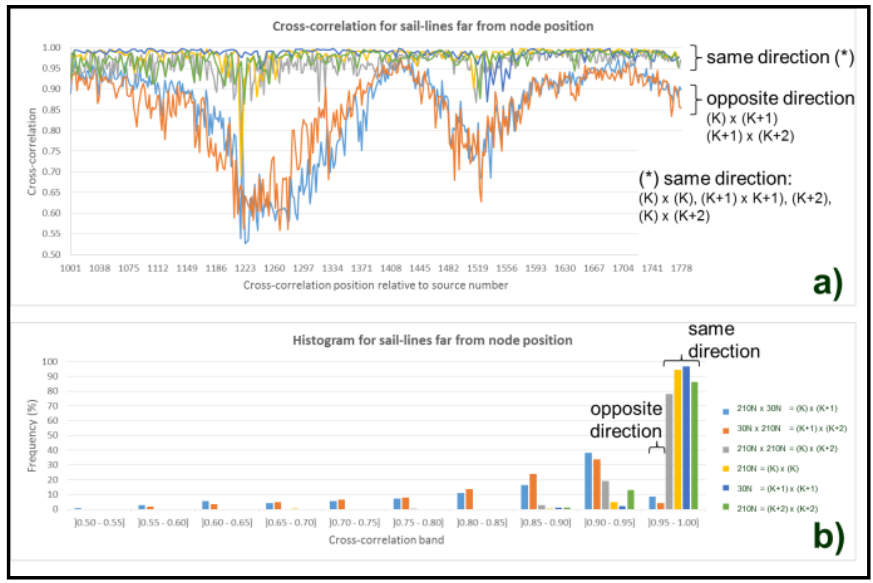

Figura 2 - Resultados das crosscorrelações entre cada par de tracos adjacentes para o conjunto de linhas mais afastadas (Ks da Tabela1): (a) gráfico estação de tiro por valor da correlação e (b) histograma dos resultados. Para o conjunto das linhas mais próximas o resultado é semelhante, mostrando a maior similaridade entre traços das SLine registradas no mesmo sentido em relação as SLines registradas no sentido oposto.

\section{Processamento 4D}

No processamento 4D, realizado pela CGG foi incluido, por solicitação da PETROBRAS, as SLines normais (primes) mais as 41 linhas adicionais redetonadas no mesma sentido do levantamento base (Figura 3).

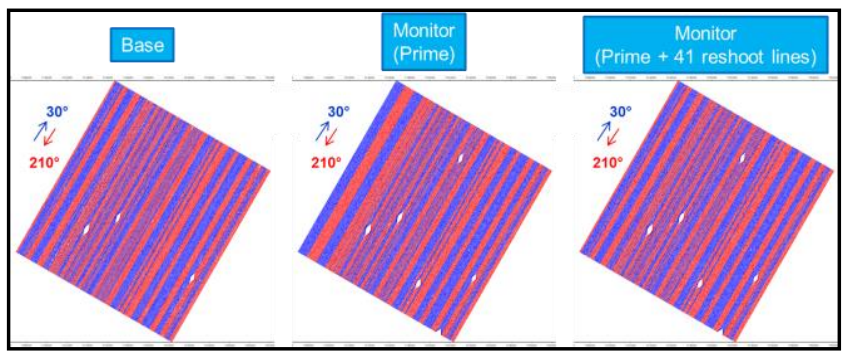

Figura 3 - Comparação entre os sentidos de registro nos levantamentos base e monitor (NE-azul, SW-vermelho).

A decisão sobre qual conjunto de dados deveria prosseguir no processamento 4D foi tomada, a partir de dados migrados, após todas as fase de préprocessamento, que incluem: atenuação de ruídos, correções relacionadas com a camada de água, correções do pulso e dos fantasmas, separação dos campos de onda e atenuação de múltiplas.

Os 3 volumes (base, monitor prime e monitor com reshoot) passaram pelo mesmo processo de binning 4D aos pares e geraram dois volumes 4D. O processo de imageamento usou apenas o campo de ondas descendentes 
Surpreendentemente, mesmo a comparação 3D realizada entre os dois volumes do levantamento monitor mostrou considerável diferença.

Nas figuras 4 e 5 são mostrados atributos de NRMS baseados em dados migrados (full stack) em três janelas distintas: em torno do Fundo do mar, no pós-Sal e no préSal.

\section{Resultados}

O resultado do processamento da CGG (Figuras 4 e 5), bem como as inferências com os dados brutos (Figura 2) mostram que o volume com base e monitor tendo todas as SLines no mesmo sentido, apresentou melhor sinal 4D.

Os valores NRMS foram até $0,5 \%$ melhores localmente. Para o volume completo, mesmo correspondendo a uma pequena faixa, restrita a porção mais a oeste do volume, a média (aritmética) variou, de 0,08 a 0,15\% sempre melhor para o volume que usou o conjunto de SLines registradas no mesmo sentido,

\section{Conclusões}

A média aritmética dos valores NRMS, relacionados com o sentido de detonação atingiu valores da ordem de $10 \%$ do sinal 4D esperado para a área, o que levou a decisão de utilizar para o restante do processamento o volume monitor em que todas as SLines tiveram o mesmo sentido de detonação do base.

Embora, possa não ter afetado as conclusões, vale destacar que a região de redetonação coincide com a porção mais ruidosa do 4D, principalmente na janela do pós-sal que não inclui o fundo do mar.

Diferentemente dos levantamentos com limitada variação azimutal ( ângulo fonte-receptor), levantamentos 4D full azimuth, como é o caso dos OBN Lula, requerem que a fonte seja simétrica e as correções do pulso sísmico, durante o processamento prevejam e corrijam, com precisão, o padrão de radiação da fonte. Limitações tecnológicas na aquisição e também no processamento ainda não permitiram tais correções.

A lição aprendida no primeiro 4D dos carbonatos do PréSal brasileiro, sinaliza a necessidade de repetição do mesmo sentido de detonação do base nos levantamentos monitores.

Vale salientar que tal obrigatoriedade causa sérias dificuldades operacionais e (ou) logísticas, sendo recomendado para os próximos levantamentos o uso de fontes o mais simétricas possíveis, que apresentem o mínimo de variação azimutal no seu padrão de radiação.

Outra necessidade é a utilização de registros do campo próximo (NFHs) o mais calibrados e estáveis possíveis para permitir que os algoritmos de correção do pulso sísmico possam eliminar as distorções azimutais da fonte em cada registro.

\section{Agradecimentos}

Agradecemos a PETROBRAS e CGG /SBGS por permitir a apresentação deste trabalho.

Agradecemos e destacamos todas as contribuições dos técnicos dos setores de geofísica da PETROBRAS (Exploração, Reservatório e Ativo de Produção do Campo de Lula).

Particularmente agradecemos a SBGS e o Setor de aquisição geofísica da PETROBRAS (EXP/GEOF/AG) pela solução logística que permitiu a redetonação das 41 linhas de fonte.

Por fim agradecemos a CGG-Rio e particularmente ao grupo técnico de processamento do 4D OBN Lula pelas discussões, sugestões e soluções encontradas nesta tarefa.

\section{References(Referências)}

Calvert R. 2005.Insights and Methods for 4D Reservoir Monitoring and Characterization. SEG/EAGE. ISBN 156080128X

E.A.Thedy, P.Dariva, W.L.Ramos Filho, P.O.Maciel Jr., F.E.F Silva \& I.B. Zorzanelli (Petrobras), 2015. Initial Results on Permanent Reservoir Monitoring in Jubarte, Offshore Brazil: $14^{\text {th }}$ International Congress of SBGf Expanded Abstracts 


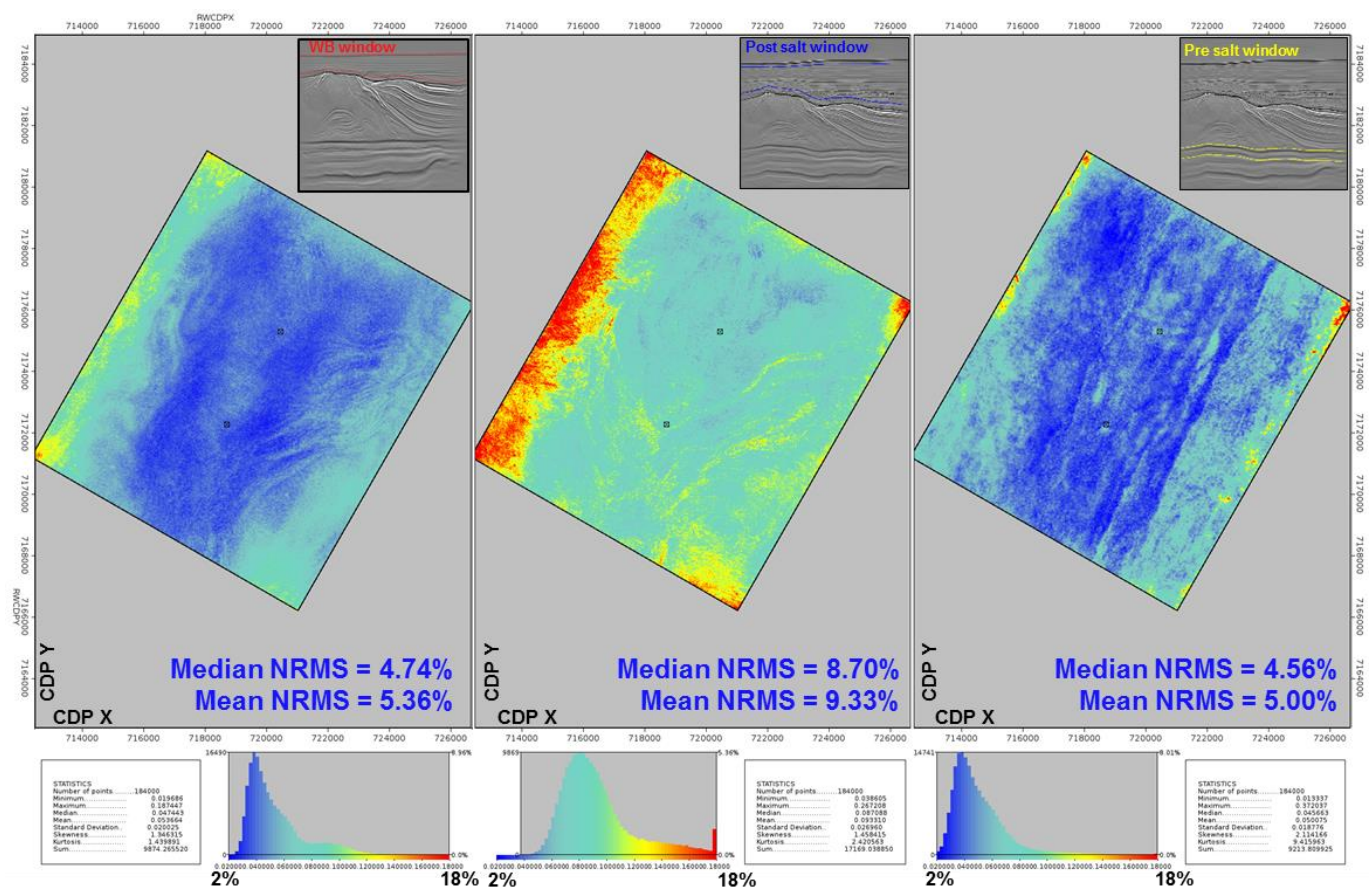

Figura 4 - Atributo NRMS: Base com Monitor (contendo linhas registradas em sentidos opostos), calculado nas janelas pós-sal (contendo a reflexão do fundo do mar), pós-sal (sem o refletor do fundo do mar) e pré-sal.

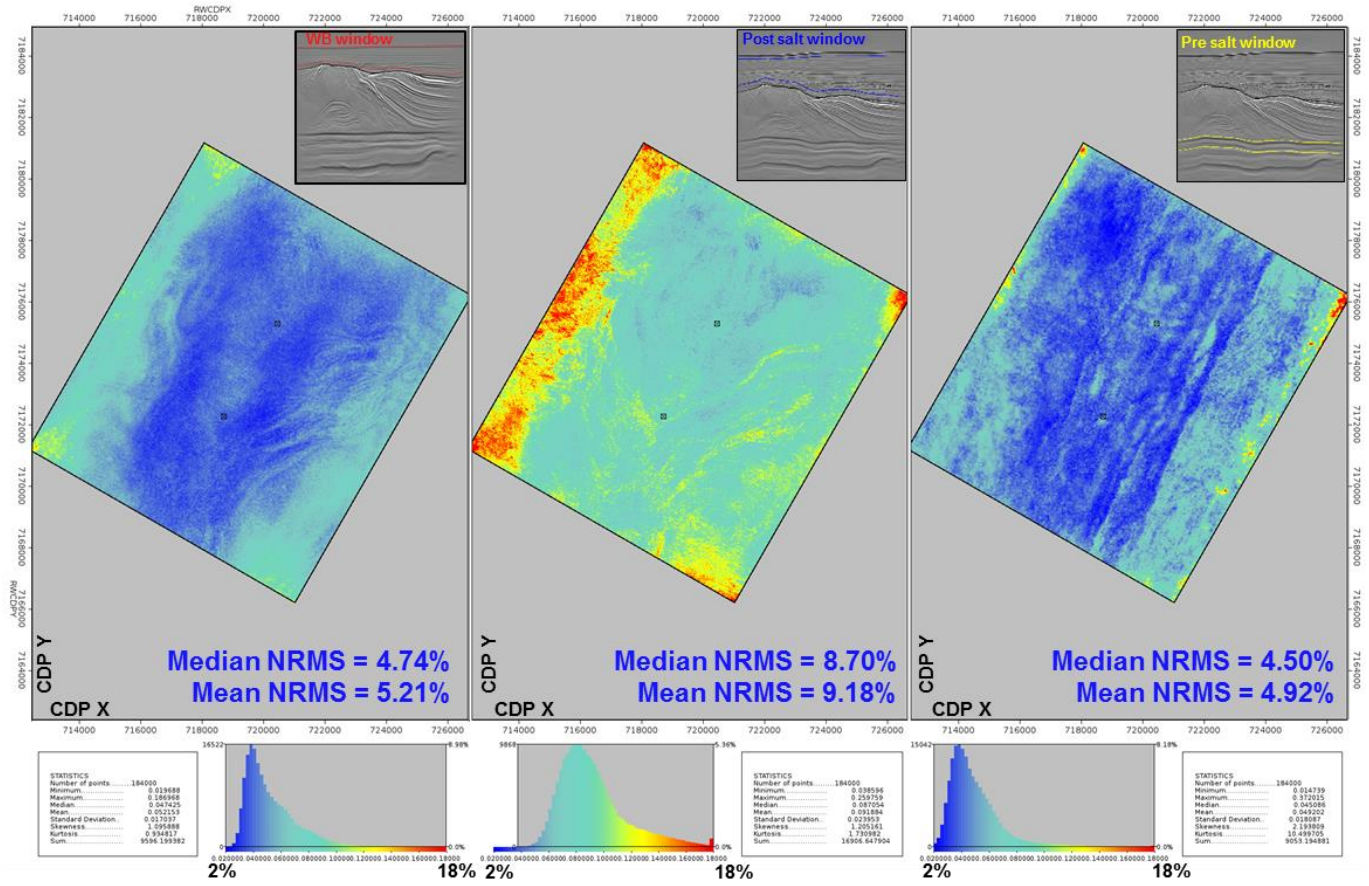

Figura 5 - Atributo NRMS Base com Monitor (todas as linhas no mesmo sentido que o base) nas mesmas janelas da Figura 4. 